Zeitschrift für Kristallographie, Bd. 117, S. 371-385 (1962)

\title{
Polymorphic forms of bismuth phosphate
}

\author{
By Rose C. I. Mooney-Slater \\ Massachusetts Institute of Technology, Cambridge, Massachusetts \\ With 5 figures
}

(Received June 12, 1962)

\begin{abstract}
Auszug
Vom Wismutphosphat ist eine Monazit-Struktur bekannt. Es ist jetzt möglich, über die Existenz zweier neuer Modifikationen zu berichten und deren Strukturen zu beschreiben. Die eine ist hexagonal vom Typ des $\mathrm{CePO}_{4} \cdot \frac{1}{2} \mathrm{H}_{2} \mathrm{O}$, die andere eine monokline Hochtemperaturform, die sich bei gewöhnlicher Temperatur sehr langsam in den Monazit-Typ umwandelt. Die hexagonale Struktur wurde aus Weissenberg-Aufnahmen, die Hochtemperatur-Struktur aus Pulveraufnahmen bestimmt. Die drei Strukturen haben gemeinsame Züge und ein Vergleich scheint anzudeuten, daß die Transformation eher displaciver als disruptiver Art ist.
\end{abstract}

\begin{abstract}
Bismuth phosphate has long been known to crystallize with the monazitetype structure. It is now possible to report the existence of two other modifications, and to describe their crystal structure. One type is hexagonal, and has the $\mathrm{CePO}_{4} \cdot \frac{1}{2} \mathrm{H}_{2} \mathrm{O}$ structure. The other is a monoclinic high-temperature form which very slowly converts to the monazite-type structure at ordinary temperatures. The structure of the hexagonal crystal has been determined from Weissenberg single-crystal data, and that of the high-temperature form from powderdiffraction data. The three structures preserve certain features in common, and intercomparison seems to indicate that the transformation from one to the other must be predominantly displacive rather than disruptive in character.
\end{abstract}

\section{Introduction}

From optical observations made on microcrystalline material, A. De Schulten (1902) found that bismuth phosphate crystallized in the monoclinic system. In 1944, at the Metallurgical Laboratory of the University of Chicago, the author used x-ray diffraction to study a large number of bismuth phosphate samples which had been prepared 
in a variety of ways by Dr. WiLliam Rubenson* and his associates. The results, which were not published except in the form of laboratory reports, showed that there are two types of bismuth phosphate crystals which exist at ordinary temperatures. One is indeed monoclinic, as observed by DE Schulten. The other is hexagonal, and ordinarily found to be slightly hydrated. A third phase, stable at high temperatures, was discovered from the evidence of a set of additional lines which appeared in monoclinic phase diffraction patterns after high-temperature drying of the samples. The monoclinic and hexagonal phases were identified as isotypes of the dimorphic modifications of the rare earth phosphates, $\mathrm{LaPO}_{4}, \mathrm{CePO}_{4}, \mathrm{PrPO}_{4}$ and $\mathrm{NdPO}_{4}$ (Mooney, 1948 a); that is, the monoclinic phase has the monazite structure, and the hexagonal phase is a second example of the new structure type found for the lanthanide phosphates.

The earlier crystallographic results have now been re-examined, confirmed and extended by a new series of experiments. The structure of the hexagonal type has been determined from single-crystal observations. The high-temperature form has been isolated, and its structure studied by means of powder diffraction data.

\section{Preparation and examination of the three phases}

Crystalline bismuth phosphate was prepared essentially by the method of DE SCHULTEN, which involves the precipitation of the product from acidified solution by slow dilution at moderately elevated temperatures. Depending on the temperature and acid concentration, the product may be hexagonal, monoclinic, or a mixture of the two phases. Lower temperature and acidity favors the growth of the hexagonal phase ${ }^{1}$. By suitable adjustment of these factors, singlephase samples of both crystal types were obtained as well-crystallized powders. Attempts to grow crystals suitable for single-crystal $x$-ray diffraction were successful only in the case of the hexagonal modification. The crystals, of tenth-millimeter dimensions, have brilliant faces, and a habit resembling quartz. The high-temperature modification was produced from crystalline precipitation products of either form, by prolonged heating at temperatures of about $800^{\circ} \mathrm{C}$. It is metastable at ordinary temperatures, and slowly converts to the monazite type.

The sequence of phase change was traced by means of differential thermal analysis and weight-loss experiments with the following results.

* Now at Brookhaven National Laboratory.

1 W. Rubenson, private communication 
Samples of hexagonal $\mathrm{BiPO}_{4}$, air dried at normal temperatures, lose about a half-molecule of water between $75^{\circ}$ and $175^{\circ} \mathrm{C}$, and suffer an exothermal reaction in the range $200^{\circ}$ to $250^{\circ} \mathrm{C}$. The product, examined by $\mathrm{x}$-rays, is found to have the monazite structure, though traces of the hexagonal type persist to temperatures as high as $350^{\circ} \mathrm{C}$. Monazite-type powders convert to the high-temperature form without weight loss, by an exothermal reaction which occurs between $600^{\circ}$ and $700^{\circ} \mathrm{C}$, and no further changes are observed in samples heated up to $1000^{\circ} \mathrm{C}$. However, even at the higher temperatures, some traces of the monazite type generally remain, and prolonged heating is required to obtain a single-phase sample of high-temperature $\mathrm{BiPO}_{4}$.

Additional experiments with hexagonal-type crystals have shown that long vacuum drying at ordinary temperature removes the water content without detectable effect on the crystal structure. Crystals dried in this manner have been kept for several years without deterioration. It appears, therefore, that though the constitution of hexagonal bismuth phosphate is ordinarily $\mathrm{BiPO}_{4} \cdot \frac{1}{2} \mathrm{H}_{2} \mathrm{O}$, the water content is not necessary to the stability of the structure.

The data used for the identification of phases and eventually for the measurement of cell constants consisted of numerous powderdiffraction patterns, some of which were obtained photographically, others by means of a recording diffractometer. In all cases, the radiation used was copper filtered through nickel, $\lambda=1.542 \AA$.

\section{Structure determination of the hexagonal modification}

The cell constants of hexagonal $\mathrm{BiPO}_{4}$ were derived from measurements of large-angle powder diffraction lines. They are compared, in Table 1, with values obtained from the analogous type of rare-earth phosphates. In the calculation of the densities, the hydration has been neglected, since it may vary with the treatment of the crystals, and is not necessarily present in the structure.

Table 1. Crystal data, $\mathrm{XPO}_{4}$, hexagonal type

\begin{tabular}{l|l|l|l|l}
\hline $\mathrm{X}$ & $a(\AA)$ & $c(\AA)$ & $c / a$ & $\varrho\left(\mathrm{g} / \mathrm{cm}^{3}\right)$ \\
\hline $\mathrm{Bi}$ & $6.966 \pm .001$ & $6.460 \pm .002$ & 0.9274 & 5.543 \\
$\mathrm{La}$ & $7.081 \pm .005$ & $6.468 \pm .008$ & 0.9134 & 4.123 \\
$\mathrm{Ce}$ & $7.055 \pm .003$ & $6.439 \pm .005$ & 0.9127 & 4.193 \\
$\mathrm{Nd}$ & $7.00 \pm .01$ & $6.39 \pm .03$ & 0.9128 & 4.368 \\
$\mathrm{Sa}$ & $6.94 \pm .01$ & $6.35 \pm .02$ & 0.9150 & 4.587 \\
$\mathrm{Gd}$ & $6.89 \pm .01$ & $6.32 \pm .02$ & 0.9172 & 4.799
\end{tabular}


In these crystals, there are three $\mathrm{XPO}_{4}$ per unit cell. The only systematic absence in the diffraction pattern is $00 l$ unless $l=3 n$. There are a number of hexagonal space groups for which the only symmetry element directly observable by $x$-rays is the three-fold screw axis. In this particular case, simple spatial considerations may be used to reduce the possibilities to two, namely, $P 3_{1} 21\left(D_{3}^{4}\right)$ and $P 6_{2} 22\left(D_{6}^{4}\right)$ or their enantiomorphs. The structure proposed for hexagonal $\mathrm{CePO}_{4}$ (MooneY, 1950) which was derived from powder data and qualitative intensities, is based on the symmetry of $P 6_{2} 22$, though $P 3_{1} 21$ was initially assumed.

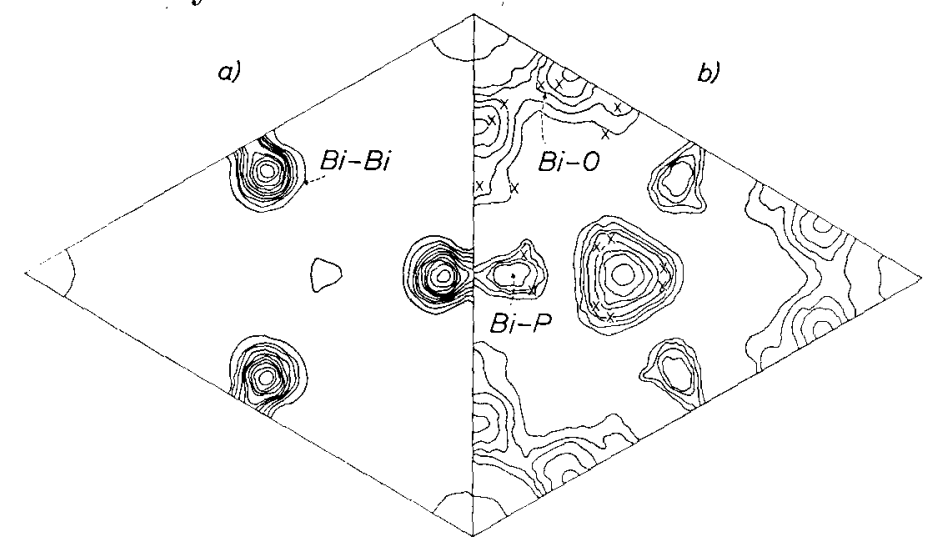

Fig. 1. Patterson synthesis, $P(u v 0)$, for hexagonal bismuth phosphate; (a) Calculated with coefficients $\left|F^{2}{ }_{\text {obs. }}\right|$; (b) Calculated with coefficients, $\left\{\left|F^{2}{ }_{\text {obs. }}\right|-\left|F^{2}{ }_{\mathrm{Bi}}\right|\right\}$. Contours are drawn at arbitrary equal intervals, except that origin peak is omitted. The principal vector-peak positions are indicated by crosses

In the case of $\mathrm{BiPO}_{4}$, for which single-crystal data has been obtained, the symmetry of $n$-level Weissenberg patterns proves conclusively that the crystal is trigonal rather than hexagonal. Therefore the space group of $\mathrm{BiPO}_{4}$ is $P 3_{1} 21$, and if it is isotypic with the rare earth phosphates in a strict sense, the space group of $\mathrm{CePO}_{4}$ must also be $P 3_{1} 21$. This is not necessarily so, despite the close similarity between the cells. If the space groups of the two crystals were different - that is, $P_{3} 21$ for $\mathrm{BiPO}_{4}$, and $\mathrm{Pb}_{2} 22$ for $\mathrm{CePO}_{4}-$ the consequent structural differences between them would be small, and entirely anolagous to the differences between $\alpha$ and $\beta$ quartz. It is not inconceivable that the hexagonal forms of $\mathrm{BiPO}_{4}$ and $\mathrm{CePO}_{4}$ should be so related. In any case, the true space-group symmetry of $\mathrm{CePO}_{4}$ and of the other hexagonal rare-earth phosphates remains a question for further inquiry. 
The data for the structure determination of $\mathrm{BiPO}_{4} \cdot \frac{1}{2} \mathrm{H}_{2} \mathrm{O}$ consisted of a set of integrated Weissenberg patterns recorded on multiple films. The crystal used was close to $0.1 \mathrm{~mm}$ in diameter. Spot densities were measured by a simple photometer, and converted to $F^{2}$ values by application of the Lorentz-polarization factor. Absorption corrections were approximated by assuming the crystal to be cylindrical.

The $F^{2}(h k 0)$ data was synthesized into the Patterson projection shown in Fig. 1a. Only the set of high Bi-Bi vector peaks are distinguishable above background. These yielded a value for the $x$ parameter of bismuth, which was subsequently used in preparing a second

\begin{tabular}{|c|c|c|c|c|c|c|c|c|c|c|c|c|c|c|}
\hline h $k 1$ & $\left|F_{0}\right|$ & {$\left[\mathbf{F}_{\mathbf{c}}\right]$} & b $k$ I & $\left|F_{0}\right|$ & $\left|\mathrm{F}_{\mathrm{c}}\right|$ & $h \mid \begin{array}{lll}h & 1\end{array}$ & $\left|F_{0}\right|$ & $\left|F_{e}\right|$ & b $k 1$ & $\left|F_{0}\right|$ & $\left|F_{\mathrm{c}}\right|$ & b k I & $\left|F_{0}\right|$ & $\left|F_{c}\right|$ \\
\hline 100 & 81 & 99 & 220 & 147 & 143 & 221 & 50 & 57 & 342 & 46 & 44 & 014 & 88 & 81 \\
\hline 200 & 185 & 202 & 320 & 32 & 36 & 231 & 17 & 10 & 432 & 79 & 86 & 104 & 120 & 118 \\
\hline 300 & 68 & 54 & 420 & 81 & 86 & 321 & 101 & 106 & & & & 114 & 106 & 100 \\
\hline 400 & 124 & 123 & 520 & 24 & 24 & 331 & 45 & 39 & 003 & 180 & 198 & 124 & 136 & 136 \\
\hline 500 & 0 & 0 & 620 & 42 & 38 & 341 & 70 & 64 & 013 & 52 & 51 & 214 & 55 & 59 \\
\hline 600 & 61 & 64 & & & & 431 & 28 & 37 & 103 & 65 & 61 & 224 & 63 & 60 \\
\hline \multirow[t]{2}{*}{700} & 32 & 33 & 330 & 120 & 122 & & & & 113 & 61 & 62 & 234 & 22 & 16 \\
\hline & & & 430 & 42 & 49 & $\begin{array}{lll}0 & 1 & 2\end{array}$ & 160 & 179 & 123 & 39 & 31 & 324 & 110 & 115 \\
\hline 110 & 106 & 107 & 530 & 89 & 91 & 102 & 114 & 124 & 213 & 47 & 46 & 334 & 38 & 42 \\
\hline 210 & 67 & 61 & & & & 112 & 103 & 106 & 223 & 108 & 98 & 344 & 71 & 75 \\
\hline 310 & 122 & 113 & 101 & 110 & 123 & 122 & 76 & 75 & 235 & 26 & 20 & 434 & 42 & 42 \\
\hline 410 & 88 & 82 & 011 & 90 & $9 !$ & 212 & 168 & 170 & 323 & 30 & 26 & & & \\
\hline 510 & 101 & 108 & 111 & 82 & 84 & 232 & 138 & 137 & 333 & 69 & 79 & & & \\
\hline 610 & 59 & 62 & 121 & 143 & 144 & 322 & 30 & 22 & 343 & 29 & 31 & & & \\
\hline 710 & 76 & 69 & 211 & 60 & 60 & 332 & 42 & 52 & 433 & 36 & 34 & & & \\
\hline
\end{tabular}

Patterson projection with the $\mathrm{Bi}-\mathrm{Bi}$ peaks removed (Fig. 1b). In this diagram, the $\mathrm{Bi}-\mathrm{P}$ vectors are readily identifiable, and indicate that the phosphorous parameter is identical with, or very close to that of bismuth. The remaining complex of superposed peaks, assumed to be predominantly $\mathrm{Bi}-\mathrm{O}$ interactions, was not directly interpreted, but served as a check for various assumed orientations of the phosphate group. This was taken as a regular tetrahedron with a $\mathrm{P}-\mathrm{O}$ distance of $1.55 \AA$. The final parameters chosen give a calculated $\mathrm{Bi}-\mathrm{O}$ vector pattern which agrees tolerably well with the density distribution observed in the Patterson diagram.

Some refinement by means of structure-amplitude calculations was attempted, but the sensitivity of this procedure was too low to be profitable with regard to the light atoms. The final bismuth position is estimated correct to within $\pm 0.03 \AA$, and the phosphorous position probably to $\pm 0.1 \AA$. No meaningful estimate can be given for the 
oxygen positions. Greater precision in the determination of the lightatom positions demands more elaborate methods than seemed justified for present purposes. However, since this crystal is representative of an interesting new type, a refinement of the structure by leastsquares methods is in preparation. The results are not expected to change the present model except in small details.

The structural arrangement of $\mathrm{BiPO}_{4} \cdot \frac{1}{2} \mathrm{H}_{2} \mathrm{O}$ (water neglected) may be described as follows:

$$
\begin{aligned}
& \mathrm{Bi}: x 0 \frac{5}{6} ; 0 x \frac{1}{6} ; \bar{x} \bar{x} \frac{1}{2} ; \text { where } x=0.466 \\
& \mathrm{P}: x \quad 0 \frac{1}{3} ; \quad 0 \quad x \frac{2}{3} ; \bar{x} \bar{x} 0 ; \quad \text { where } x=0.466 \\
& \mathrm{O}: x y z ; \bar{y} x-y \frac{1}{3}+z ; \quad y-x \bar{x} \frac{2}{3}+z ; \\
& y x \bar{z} ; \quad x-y \bar{y} \frac{2}{3}-z ; \bar{x} y-x \frac{1}{3}-z
\end{aligned}
$$

where, for $\mathrm{O}_{1}, x_{1}=0.418 ; y_{1}=0.162 ; z_{1}=0.460$, and for $\mathrm{O}_{2}, x_{2}=0.663$; $y_{2}=0.135 ; z_{2}=0.182$.

The calculated and experimental structure amplitudes are compared in Table 2 . The calculated values have been scaled to the observations by the factor $\exp \left[-\beta \sin ^{2} \theta / \lambda\right]$ where $\beta=0.968 \AA^{2}$. The residual factor, $R=\Sigma\left|F_{o}-F_{c}\right| / \Sigma\left|F_{o}\right|$ has the value, 0.07 .

Figure 2 shows the hexagonal bismuth-phosphate structure projected along the $c$ axis. The striking feature of this structure, as it is in hexagonal $\mathrm{CePO}_{4}$, is the open, oxygen-lined tunnels extending through the crystal along the $c$ axis. The distances from a given oxygen to its nearest oxygen neighbors therefore have an unusual range of values; conventional ones within the network, such as 2.73 and $3.1 \AA$, and very large ones, i. e. $5.47 \AA$, to nearest neighbors across the open channel. If the water is interstitial, and is lodged at intervals along the $c$ axis, the space available is just sufficient to accomodate a statistical distribution of $3 / 2$ molecule per cell.

The presence of water is probably a necessary factor in the formation of this crystal type, and no doubt exercises a stabilizing influence on the structure. However, as has been seen, its removal at ordinary temperatures does not lead to the breakdown of the structure. This is understandable from the nature of the framework, which is well coordinated within itself. Each bismuth is surrounded by eight oxygens, four at distances of $2.33 \AA$ (tetrahedron corners), and four at longer distances of $2.66 \AA$ (tetrahedron edges). Thus each phosphate group is coordinated to six bismuths, and each oxygen is bound to two bismuths by one long and one short bond. 
The arrangement of the atoms in the structure is such that the longer coordination distances essentially determine the $c$ periodicity, and the shorter ones govern the spacing in the $a b$ plane. From the table of cell dimensions, it is interesting to note that the $c / a$ ratio for $\mathrm{BiPO}_{4} \cdot \frac{1}{2} \mathrm{H}_{2} \mathrm{O}$ is significantly larger than it is in the series of rareearth phosphates. Apparently, the disparity in the coordination dis-

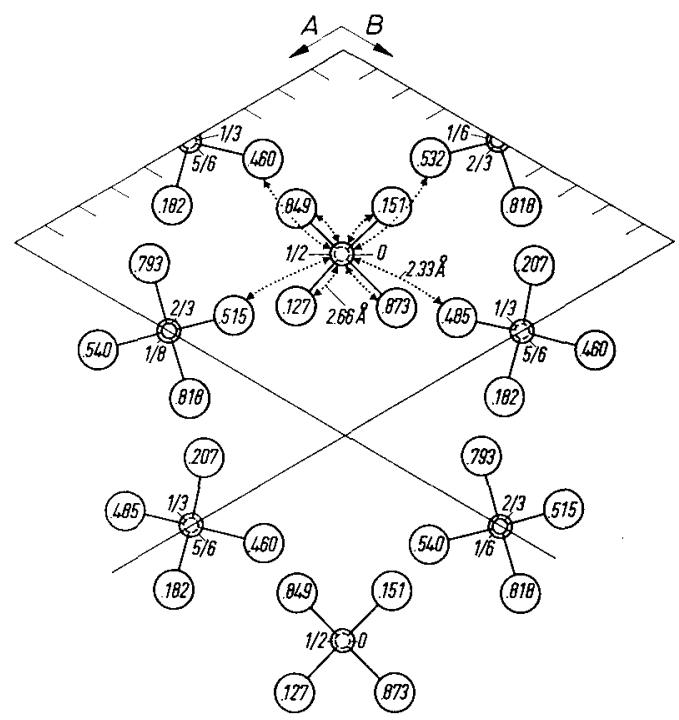

Fig. 2. Structure of hexagonal bismuth phosphate, projected along the unique axis. The circles, in descending order of size, represent $\mathrm{O}, \mathrm{Bi}$ and $\mathrm{P}$. Numerical values of $z / c$ are given, and the coordination of one $\mathrm{Bi}$ is shown

tances tends to be smaller in the rare-earth structures, perhaps because bismuth has the greater tendency toward covalency.

\section{Concerning the monazite-type structure}

In the present study, as in the earlier investigations in 1944, the room temperature monoclinic phase of $\mathrm{BiPO}_{4}$ was prepared as a wellcrystallized powder. Without single-crystal data, it was not possible to extend the original results. The cell dimensions of the crystal, determined from large-angle powder lines, are given in Table 3, along with comparable data from a series of monoclinic rare-earth phosphates.

The intensities as well as the spacings of the $\mathrm{BiPO}_{4}$ pattern follow closely those observed for the rare-earth phosphates. The structure 
Table 3. Crystal data for monazite-type crystals, $\mathrm{XPO}_{4}$

\begin{tabular}{c|l|l|l|c|c}
\hline $\mathrm{X}$ & \multicolumn{1}{|c|}{$a(\AA)$} & \multicolumn{1}{|c|}{$b(\AA)$} & $c(\AA)$ & $\beta$ & $\varrho\left(\mathrm{g} / \mathrm{cm}^{3}\right)$ \\
\hline $\mathrm{Bi}$ & $6.74 \pm .02$ & $6.92 \pm .02$ & $6.46 \pm .02$ & $103^{\circ} 30^{\prime}$ & 6.83 \\
$\mathrm{La}$ & 6.83 & 7.05 & 6.48 & $103^{\circ} 34^{\prime}$ & 5.09 \\
$\mathrm{Ce}$ & 6.76 & 7.00 & 6.44 & $103^{\circ} 38^{\prime}$ & 5.23 \\
$\mathrm{Pr}$ & 6.75 & 6.94 & 6.40 & $103^{\circ} 21^{\prime}$ & 5.34 \\
$\mathrm{Nd}$ & 6.71 & 6.92 & 6.36 & $103^{\circ} 28^{\prime}$ & 5.50
\end{tabular}

must therefore conform to the atomic arrangement known as the monazite type.

Monazite-type crystals have the symmetry $P 2 / n\left(C_{2 h}^{5}\right)$, as indicated by the systematic absence of reflections $h 0 l$ unless $h+l=2 n$. The cell contains four $\mathrm{MXO}_{4}$, and all of the atoms are in general positions. Structural parameters for the mineral, (Ce,La,Di)PO $\mathrm{P}_{4}$ have been deduced from single-crystal data (KokKonos, 1942) and also for laboratory-prepared $\mathrm{CePO}_{4}$ from powder data (MooneY, $1948 \mathrm{a}$ ). In both cases, the cation positions were derived from intensity considerations, and the phosphate-group positions were assumed from the nature of the spaces between the cations. In the published reports, the cell origins adopted by the two authors differ by $b / 2$; the parameters are referred to different atoms of the equipoint sets, and there is a typographical error in one of the parameters given for $\mathrm{CePO}_{4}$. For convenient reference, the two independently determined sets of parameters are given here in comparable form.

Table 4. Parameters for the monazite structure

\begin{tabular}{l|r|r|r|r|r|r|r}
\hline & \multicolumn{3}{|c|}{$\mathrm{CePO}_{4}$} & & \multicolumn{3}{|c}{ (Ce,La,Di) $\mathrm{PO}_{4}$} \\
\cline { 2 - 7 } & $x / a$ & $y / b$ & $z / c$ & & $x / a$ & $y / b$ & $z / c$ \\
\hline $\mathrm{Ce}$ & 0.292 & 0.156 & 0.083 & $\mathrm{X}$ & 0.286 & 0.158 & 0.094 \\
$\mathrm{P}$ & .292 & .156 & .581 & $\mathrm{P}$ & .325 & .167 & .611 \\
$\mathrm{O}_{1}$ & .211 & .990 & .423 & $\mathrm{O}_{1}$ & .306 & .992 & .472 \\
$\mathrm{O}_{2}$ & .374 & .323 & .464 & $\mathrm{O}_{2}$ & .375 & .342 & .500 \\
$\mathrm{O}_{3}$ & .467 & .070 & .765 & $\mathrm{O}_{3}$ & .500 & .133 & .806 \\
$\mathrm{O}_{4}$ & .116 & .235 & .680 & $\mathrm{O}_{4}$ & .128 & .200 & .681
\end{tabular}

Though the parameters differ somewhat, the structural arrangement deduced from the two independent studies is essentially the same. The monazite or the $\mathrm{CePO}_{4}$ structure may equally well be described as a three-dimensional, space-filling network in which the cation has an irregular coordination of eight oxygens. From each cation, four short bonds, given as $2.37 \AA$ in $\mathrm{CePO}_{4}$, and $2.46 \AA$ in 
monazite, extend to the corners of four different phosphate groups. Four longer bonds, $2.66 \AA$, connect to the edges of two additional phosphate tetrahedra (Fig. 3).

It was shown by ZwManN (1949) that the powder intensities of $\mathrm{BiPO}_{4}$ are quite well accounted for by the monazite parameters given by Kokzoros. The author's attempts to derive parameters from the

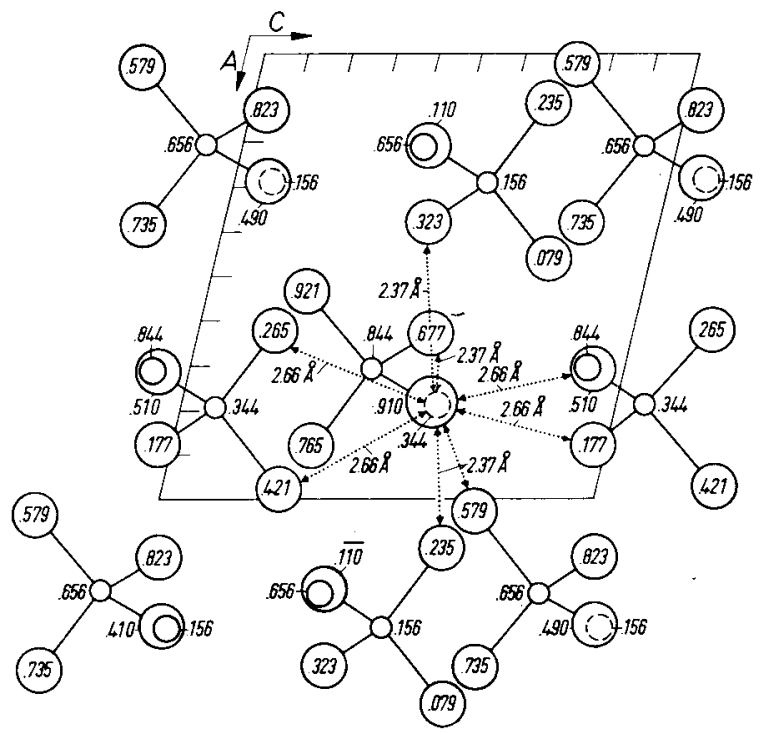

Fig. 3. Representative monazite type crystal structure $\left(\mathrm{CePO}_{4}\right)$, projected along the $b$ axis

bismuth-phosphate intensities resulted in values indistinguishable from $\mathrm{CePO}_{4}$ or from monazite. Therefore, the $\mathrm{CePO}_{4}$ structure, illustrated in Fig. 3, will be used as a model of monazite-type $\mathrm{BiPO}_{4}$, for comparison with the two other modifications of the compound.

\section{Structural study of the high-temperature modification}

The data used to study the high-temperature form of bismuth phosphate consisted of powder-diffraction patterns obtained from a recording diffractometer by means of copper radiation filtered through nickel, that is, $\lambda=1.542 \AA$. The samples, after the long heat treatment required for removing all traces of the monazite type, were well crystallized, and gave diagrams of excellent quality. However, the pattern is complex, and, because of increasingly troublesome superposition of lines, measurements were carried out only to values of $2 \theta$ of about $75^{\circ}$. 
Table 5 shows data from a pattern prepared under experimental conditions for moderately high resolution. The $I(\mathrm{obs})$ values given are simply the relative peak heights. The pattern was indexed by a process of trial and error, facilitated by the observation of certain coincidences between the lines of this pattern and those of the monazite pattern. It happens that the $b$ axes of the two crystals are not very different. The results of the indexing are consistent with a monoclinic cell of the following dimensions:

$$
\begin{gathered}
a=4.88 \pm 0.03 \AA ; b=7.06 \pm 0.02 \AA ; c=4.71 \pm 0.03 \AA ; \\
\beta=96.3^{\circ} \pm 0.5^{\circ}
\end{gathered}
$$

If there are two $\mathrm{BiPO}_{4}$ per unit cell, as indicated by the cell volume, the calculated density is $6.22 \mathrm{~g} / \mathrm{cm}^{3}$. There is only one systematic absence in the diffraction pattern; that is, $0 k 0$ is absent unless $k$ is

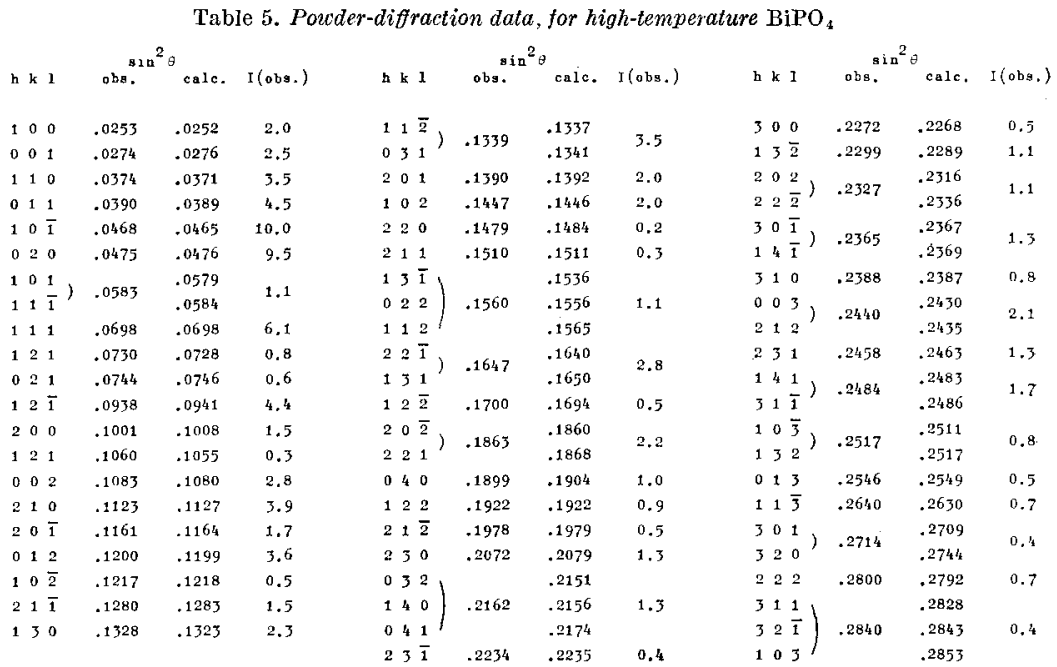

even. On this evidence, the space group may be either $P 2_{1}\left(C_{2}^{2}\right)$ or $P 2_{1} / m\left(C_{2 h}^{2}\right)$.

Because of the inherent deficiencies of powder data, particularly for a complex pattern, and because, in this case, large-angle measurements were not obtained, it did not seem feasible to attempt more than an approximate description of the structure. However, the smallness of the cell and the presence of the heavy atom make it possible to deduce at least the gross features of the structural arrangement from powder-diffraction data. 
The lower-symmetry space group was adopted for generality, and also from simple space considerations. This symmetry requires the distribution of the atoms in two-fold general positions, $x, y, z ; \bar{x}, y+\frac{1}{2}, \bar{z}$. Obviously, the high scattering due to bismuth must dominate the diffracted intensities. On the assumption that, in general, the diffracted intensities are not greatly modified by the light-atom contributions, approximate bismuth parameters were deduced by intercomparison of observed intensities. However, there are a few observations which give strong evidence for the location of the phosphate group. For instance, reflections 020 and 040 are higher than can be accounted for without a substantial contribution from the light atoms. This is true also of $10 \overline{1}$, while 101 is quite low. From considerations of this kind, and with the additional condition that the distances between oxygens of different tetrahedra must remain reasonable, phosphate groups were fitted into the spaces between the cation positions. The groups were assumed to be regular tetrahedra with $\mathrm{P}-\mathrm{O}$ distances of $1.55 \AA$.

This procedure limited the position and orientation of the phosphate group to a fairly small range, within which no sharp distinctions could be made. After trial of a number of models, differing slightly in the position of bismuth as well as of the phosphate group, the following parameters (Table 6) were chosen to represent a satisfactory approximation of the structural arrangement.

Table 6. Approximate structural parameters for high-temperature $\mathrm{BiPO}_{4}$

\begin{tabular}{l|r|r|r}
\hline & $x / a$ & $y / b$ & $z / c$ \\
\hline $\mathrm{Bi}$ & 0.144 & 0 & 0.175 \\
$\mathrm{P}$ & .310 & $\frac{1}{2}$ & .325 \\
$\mathrm{O}_{1}$ & .220 & .332 & .125 \\
$\mathrm{O}_{2}$ & .108 & .668 & .257 \\
$\mathrm{O}_{3}$ & .607 & .561 & .278 \\
$\mathrm{O}_{4}$ & .300 & .439 & .640
\end{tabular}

The observed and calculated intensities are plotted for comparison in Fig. 4. The $I$ (obs.) values are measurements of peak areas from suitably prepared diffractometer traces, with no corrections other than the Lorentz-polarization factor. The calculated intensities are values of $P F^{2}$, where $F$ is the structure factor and $P$ the multiplicity. The overall agreement between them is sufficiently good to indicate that the parameters describe at least the general nature of the structure. 
The proposed structural arrangement is illustrated in Fig. 5. Interatomic distances calculated from the parameters are, of course, tentative. In this model, bismuth is surrounded by eight oxygens at an

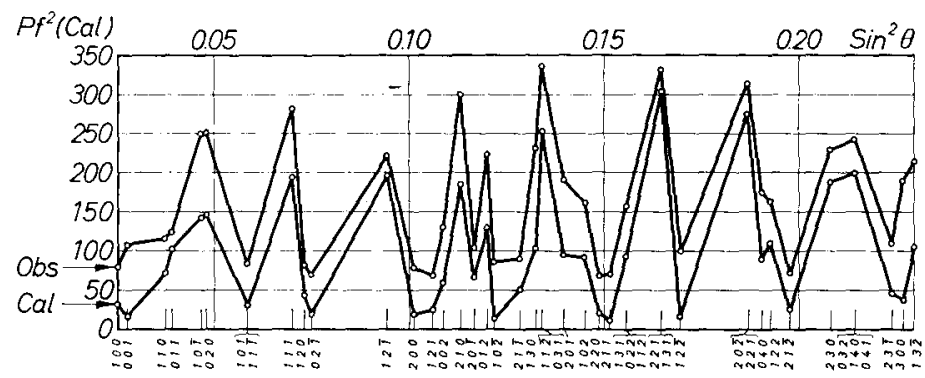

Fig. 4. Diagrammatic comparison of calculated and observed intensities (arbitrary scale) for the high-temperature modification of bismuth phosphate

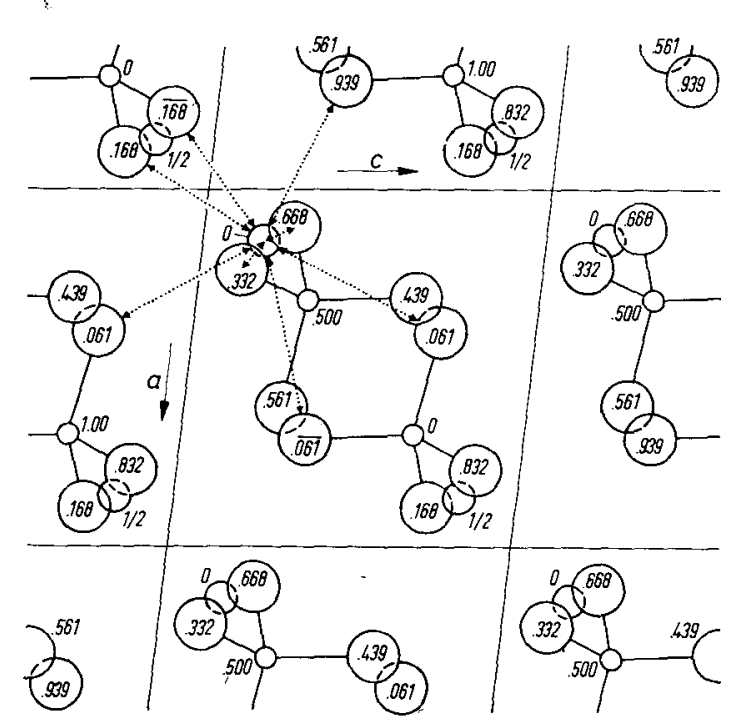

Fig. 5. Structure of the high-temperature modification of bismuth phosphate. The average value of the eight coordination distances is $2.55 \AA$

average distance of $2.55 \AA$. The values fall into two groups; six are close to $2.47 \AA$, and two average $2.78 \AA$. The closest oxygen-oxygen distance between different tetrahedra is $2.5 \AA$. In the different models tested, individual distances vary considerably, but the overall average is not materially changed. 
The author is grateful for the valuable assistance of JOSEPH P. WRIGHT in testing a large number of models by means of structure amplitudes calculated on the M.I.T. 709 computer.

\section{Comparison of the three erystal modifications of $\mathrm{BiPO}_{4}$}

A comparison of the structure diagrams (Figs. 2, 3, and 5) shows that the three modifications of bismuth phosphate have a certain structural element in common. This configuration consists of a chain of bismuth atoms alternating with phosphate groups, in which each bismuth links its two adjacent phosphate groups by edges. These chains extend in the direction of the unique axis in the hexagonal crystal; along the $c$-axial direction in the monazite type; and along the $a-c$ diagonal direction in the high-temperature modification. In all three crystals, each such chain is cross-linked to four neighboring chains by bonds which extend from bismuth to phosphate tetrahedron corners, and which are roughly perpendicular to the chain direction.

The differences between the structures, most striking in the hexagonal case, are a consequence of differences in the mutual orientation of the chains. In the hexagonal crystal, their highly symmetrical arrangement results in an open framework structure. In the monazite-type crystal, the chains, less symmetrically arranged, build up a compact, space-filling network. As a result, there is an extraordinary difference of density, amounting to about twenty per cent, between these two forms of bismuth phosphate. In the transition from the monazite type to the high-temperature form, the rearrangement of the chains is such as to change the crystal symmetry from $P 2_{1} / n$ to $P 2_{1}$ and to decrease the density by about ten percent, from $6.83 \mathrm{~g} / \mathrm{cm}^{3}$ to 6.22 $\mathrm{g} / \mathrm{cm}^{3}$. In all three crystals, the coordination may be said to be eight, and to consist of two definitely unequal sets of $\mathrm{Bi}-\mathrm{O}$ distances.

The transitions from one to the other of these modifications, as the temperature rises, can scarcely be pictured as cataclysmic. Though presumably requiring a minimum of bond rupture, they are probably effected in large part by directional changes in the four $\mathrm{Bi}-\mathrm{O}$ bonds which are transverse to the chains. Single crystals of the hexagonal type, when heated above the transition point, lose their transparency, but are otherwise unchanged in appearance. X-ray diffraction patterns show that such pseudomorphs are essentially bundles of oriented monazite-type needles. The $c$-axial direction lies along the original hexagonal axis, and the $a$ and $b$ directions are randomly oriented. 
To recapitulate, the monazite type is the stable form of $\mathrm{BiPO}_{4}$ over a long temperature range. The transition from the hexagonal to the monazite type is not reversible. The high-temperature structure slowly converts to the monazite type at ordinary temperatures. No spontaneous change from the hexagonal to the monazite type has been detected.

\section{Concluding remarks}

Though the empirical ionic radii of bismuth and of the rare-earth elements are quite comparable, isomorphism between their analogous compounds is rather the exception than the rule. There are at least three crystalline modifications of $\mathrm{Bi}_{2} \mathrm{O}_{3}$, and three of the rare-earth oxides, yet none of these structures are alike. The trihalide structures also are unrelated, but the oxyhalides are isotypic (WyскоFF, 1948). Two modifications of the phosphates which have been discussed are isotypic, but the existence of a high-temperature form of the rareearth phosphates has not been reported.

All of the known examples of the hexagonal $\mathrm{CePO}_{4} \cdot \frac{1}{2} \mathrm{H}_{2} \mathrm{O}$ type are phosphates. In addition to those which have been mentioned previously, only $\mathrm{AcPO}_{4} \cdot \frac{1}{2} \mathrm{H}_{2} \mathrm{O}$ (Zachariasen, 1949), $\mathrm{PuPO}_{4} \cdot \frac{1}{2} \mathrm{H}_{2} \mathrm{O}$, and $\mathrm{YPO}_{4} \cdot x \mathrm{H}_{2} \mathrm{O}$ (MooNey, unpublished) can be added.

The monazite structure is represented by a variety of chemically different compounds, $\mathrm{M}^{n+}\left(\mathrm{XO}_{4}\right)^{n-}$, where $n$ may be 2,3 , or 4 . The examples include crocoite, $\mathrm{PbCrO}_{4}$, and strontium chromate, $\mathrm{SrCrO}_{4}$ (Strukturbericht, 1928-32); bismuth arsenate, bismuth phosphate and the rare-earth phosphates; Huttonite, $\mathrm{ThSiO}_{4}$, a natural thorium silicate (PABST, 1950). All of these crystals are dimorphic. Unstable forms of lead chromate and strontium chromate have the barite structure; bismuth phosphate and the rare-earth phosphates have, as an alternative structure, the hexagonal $\mathrm{CePO}_{4} \cdot \frac{1}{2} \mathrm{H}_{2} \mathrm{O}$ structure, but bismuth arsenate (Mooney, $1948 \mathrm{~b}$ ), under suitable conditions, crystallizes with the scheelite structure. Thorite, a commonly known thorium silicate, has the tetragonal zircon structure.

This work has been supported by the National Seience Foundation.

\section{References}

M. A. De Schulten (1903), Production de sels de bismuth crystallisés. Bull. Soc. Chim. Paris 29, 723.

M. P. Kokkonos (1942), La structure de la monazite. Praktika der Athener Akademie 17, 163-174. 
R. C. L. Mooney (1948a), Crystal structures of a series of rare earth phosphates. J. Chem. Physies 16, 1003.

R. C. L. Mooney (1948b), Crystal structure of tetragonal bismuth arsenate. Acta Crystallogr. 1, 163-165.

R. C. L. Mooney (1950), X-ray diffraction study of cerous phosphate $\left(\mathrm{CePO}_{4}\right)$, hexagonal modification. Acta Crystallogr. 3, 337-340.

A. PABst (1950), Monoclinic thorium silicate. Nature [London] 166, 187 and 590. R. W. G. Wyckoff (1948), Crystal Structures. V. III. Interscience Publishers, Inc., New York.

Strukturbericht 2 (1928-32) 448-449.

W. H. Zachartasen (1949), Crystal chemical studies of the $5 f$ series of elements. XII. New compounds representing known structure types. Acta Crystallogr. 2, 388-390.

J. Zemans (1949), Beiträge zur Kristallchemie des Wismuts. Tschermak's Mineralogische und Petrographische Mitteilungen [3] 1, 361-378. 